\title{
COMPARITIVE STUDY OF INTUBATING CONDITIONS OF SUXAMETHONIUM AND MIVACURIUM CHLORIDE AS INTUBATING AGENTS IN PAEDIATRIC PATIENTS POSTED FOR TONSILLECTOMIES
}

Vasantha Kumar J11, Dayananda V.P2 , G.S. Venkatesh ${ }^{3}$

\section{HOW TO CITE THIS ARTICLE:}

Vasantha Kumar J, Dayananda V.P, G.S. Venkatesh. "Comparative Study of Intubating Conditions of Suxamethonium and Mivacurium Chloride as Intubating Agents in Paediatric patients posted for Tonsillectomies". Journal of Evolution of Medical and Dental Sciences 2014; Vol. 3, Issue 02, January 13; Page: 279-288, DOI:10.14260/jemds/2014/1822

ABSTRACT: BACKGROUND: Suxamethonium, a depolarizing muscle relaxant has remained the undisputed drug for aiding intubation and an ideal drug for securing the airway because of its capabilities to produce excellent intubating conditions within 60 seconds \& short duration of action but is contraindicated in certain clinical conditions because of its side effects.AIM: The present study was undertaken to compare the intubating conditions as well as duration of actions of Suxamethonium $1 \mathrm{mg} \mathrm{kg}^{-1}$ and mivacurium chloride, a new benzylisoquinolium non-depolarizing muscle relaxant with relatively rapid onset and short duration of action, $0.25 \mathrm{mg} \mathrm{kg}^{-1}$ at 60 seconds. METHODS: After institutional approval and informed consent, 60 ASA I and II pediatric patients posted for elective tonsillectomies were grouped into 30 patients each. We compared the intubating conditions and duration of action of Suxamethonium $1 \mathrm{mg} \mathrm{kg}^{-1}$ and mivacurium chloride $0.25 \mathrm{mg} \mathrm{kg}^{-1}$ at 60 seconds. Cardiovascular responses and any side effects related to histamine release were also studied. Statistical analysis: Statistical tools used in present study are student't' test and 'chi squared' test. RESULTS: In group I, the intubating conditions in all the 30 patients were excellent except in 1 patient.In group II, 18 out of 30 patients had excellent intubating conditions, 7 patients had good, 3 patients fair and 2 patients had poor intubating conditions. CONCLUSIONS: The present study concluded that Suxamethonium produces excellent intubating conditions in $100 \%$ and mivacurium produces good to excellent intubating conditions in $83 \%$ at 60 seconds. Mivacurium chloride can be employed when Suxamethonium is contraindicated but Suxamethonium remains superior to mivacurium

KEYWORDS: Intubation, Muscle relaxant, Airway, Mivacurium, Suxamethonium

INTRODUCTION: Before the concept of balanced anesthesia came into vogue, the only way to relax the muscles was to produce deep anesthesia with an inhalational agent, which had deleterious hemodynamic effects and often produced stormy intubations.

The introduction of muscle relaxants into clinical practice changed the whole scenario of anesthetic management of patients. Suxamethonium, a depolarizing muscle relaxant has remained the undisputed drug for aiding intubations both in elective and emergency cases. Its capability to produce excellent intubating conditions within 60 seconds with short duration of action makes it an ideal drug for securing the airway. However, it falls short of an ideal muscle relaxant because of its side effects like cardiac arrhythmias and hyperkalemia. Its use is relatively contraindicated in patients with burns, intraperitoneal sepsis and various neuromuscular disorders. 
In various clinical conditions, where Suxamethonium is contraindicated, there is a need for non-depolarizing muscle relaxant which is capable of producing adequate intubating conditions at 60 seconds like Suxamethonium but without its side effects.

Mivacurium chloride is a new benzylisoquinolium non-depolarizing neuromuscular blocking agent with relatively rapid onset and short duration of action. It is proposed that mivacurium chloride may provide the anesthesiologist with an alternative to Suxamethonium.

MATERIAL AND METHODS: A clinical study comparing the intubating conditions of Suxamethonium $1 \mathrm{mg} \mathrm{kg}^{-1}$ with mivacurium chloride $0.25 \mathrm{mg} \mathrm{kg}^{-1}$ at 60 seconds was undertaken at K.R. Hospital, Mysore, attached to Government Medical College after obtaining ethical committee clearance.

The study population consisted of 60 pediatric patients of ASA class I and Class II belonging to both sexes in the age group of 5 to13 years who were posted for elective tonsillectomies.The informed consent was obtained from the parents / guardians of the patients. The exclusion criteria consisted of patients with co-existing cardiovascular diseases, bronchial asthma, hepatic, renal diseases or with airway abnormalities.

The study population was randomly divided into two groups with 30 patients in each group.

Group I consisting of 30 patients were to receive Suxamethonium $1 \mathrm{mg} \mathrm{kg}^{-1}$ bodyweightand intubation was attempted at 60 seconds.

Group II consisting of 30 patients were to receive mivacurium chloride $0.25 \mathrm{mg} \mathrm{kg}^{-1}$ bodyweight and intubation was to be attempted at 60 seconds.

A thorough pre-anesthetic evaluation was done a day before surgery and all the necessary investigation were done.

On the day of surgery, after the patients had been shifted to the operating room, an intravenous line was secured with an appropriate sized intravenous cannula and patient was connected to multichannel monitor consisting of pulse oximeter, electro-cardiogram, heart rate and noninvasive blood pressure.

The base line heart rate, oxygen saturation and electro cardiogram, systolic, diastolic and mean arterial blood pressures were recorded.

Injection atropine $0.02 \mathrm{mg} \mathrm{kg}^{-1}$ and injection pentazocine $0.5 \mathrm{mg} \mathrm{kg}^{-1}$ bodyweight was given intravenously five minutes before the induction of anesthesia as pre- medication.

All the patients were pre-oxygenated with 100\% oxygen via a face mask for 3 minutes before the induction of anesthesia. They were induced with injection thiopentone sodium $5 \mathrm{mg} \mathrm{kg}^{-1}$ bodyweight intravenously.

In Group I, Suxamethonium $1 \mathrm{mg} \mathrm{kg}^{-1}$ was given intravenously after the loss of eyelash reflex and ventilated with $100 \%$ oxygen via the face mask.

Similarly, in Group II, Mivacurium chloride $0.25 \mathrm{mg} \mathrm{kg}^{-1}$ was given intravenously after the loss of eyelash reflex and ventilated with $100 \%$ oxygen via the face mask.

In both the groups, nasal intubation was attempted at 60 seconds following the administration of muscle relaxants and intubating conditions were graded using R. Cooper, R.K. Mirakur et al. 1994 classification as follows: 


\begin{tabular}{|c|c|c|l|}
\hline Score & Jaw relaxation & Vocal cords & \multicolumn{1}{|c|}{ Response to intubation } \\
\hline 0 & Poor & Closed & Severe coughing \\
\hline 1 & Minimal & Closing & Mild coughing \\
\hline 2 & Moderate & Moving & Slight diaphragmatic contraction \\
\hline 3 & Good & Open & None \\
\hline
\end{tabular}

Depending on the total score obtained, adequacy of intubating conditions was assessed as follows:

\begin{tabular}{|c|c|}
\hline Excellent & $8-9$ \\
\hline Good & $6-7$ \\
\hline Fair & $3-5$ \\
\hline Poor & $0-2$ \\
\hline
\end{tabular}

All the patients were intubated with appropriate sized nasal endotracheal tubes (plain), bilateral air entry was checked and the tube was secured firmly.

Maintenance of anesthesia was done with $50 \%$ oxygen and $50 \%$ nitrous oxide and IPPV was done with a Jackson Rees modification of Ayre's T piece [if the patient weighed less than $20 \mathrm{~kg}$ ] or Bain's modification of Mapleson 'D' circuit [if the patient weighed more than $20 \mathrm{~kg}$ ].

The duration of action of initial bolus doses of Suxamethonium and mivacurium chloride were noted. Subsequently, the muscle relaxation was maintained with vecuronium bromide, $0.04 \mathrm{mg}$ $\mathrm{kg}^{-1}$ body weight till the end of surgery as we had limited stock of mivacurium.

Monitoring of vital parameters like heart rate, oxygen saturation, systolic, diastolic and mean arterial blood pressures, electro cardiogram were recorded 1, 3 and 5 minutes following intubation.

At the end of the surgery all the patients were reversed with injection neostigmine $0.05 \mathrm{mg}$ $\mathrm{kg}^{-1}$ body weight and injection atropine $0.02 \mathrm{mg} \mathrm{kg}^{-1}$ body weight.

Other side effects like histamine releasing property associated with administration of these muscle relaxants were also noted.

Statistical tools used in present study are student' $t$ ' test and chi-squared test.

RESULTS: In this study, 60 pediatric patients undergoing tonsillectomies under general anesthesia were grouped in to two groups and the intubating conditions were compared at 60 seconds either with Suxamethonium $1 \mathrm{mg} \mathrm{kg}^{-1}$ bodyweight or with mivacurium chloride0.25 mg kg${ }^{1}$ bodyweight.There were no significant differences between the two groups with respect to age, weight and sex distribution.

The mean dose of Suxamethonium used was $23.53 \mathrm{mg}$ and the maximum and minimum doses were $40 \mathrm{mg}$ and $10 \mathrm{mg}$ respectively (Table-1).The mean dose of Mivacurium Chloride used was $5.15 \mathrm{mg}$ with a maximum and minimum does of $9 \mathrm{mg}$ and $3.25 \mathrm{mg}$ respectively (Table-2). 


\begin{tabular}{|c|c|c|}
\hline DOSE & NO. OF PATIENTS & PERCENTAGE \\
\hline $10-20 \mathrm{mg}$ & 13 & 43.3 \\
\hline $21-30 \mathrm{mg}$ & 13 & 43.3 \\
\hline $31-40 \mathrm{mg}$ & 4 & 13.3 \\
\hline Mean dose & $23.53 \mathrm{mg}$ \\
\hline Maximum dose & $40 \mathrm{mg}$ (Case No.22) \\
\hline Minimum dose & $10 \mathrm{mg}$ (Case No's 1 \& 14) \\
\hline \multicolumn{2}{|c|}{ TABLE-1: Dose of Suxamethonium }
\end{tabular}

\begin{tabular}{|c|c|c|}
\hline DOSE & NO. OF PATIENTS & PERCENTAGE \\
\hline $3.25-5 \mathrm{mg}$ & 19 & 63.3 \\
\hline $5.25-7 \mathrm{mg}$ & 10 & 33.3 \\
\hline $7.25-9 \mathrm{mg}$ & 1 & 3.3 \\
\hline Mean dose & $5.15 \mathrm{mg}$ \\
\hline Maximum dose & $9 \mathrm{mg}$ (Case No.2) \\
\hline Minimum dose & \multicolumn{2}{|c|}{$3.25 \mathrm{mg}$ (Case No. 18) } \\
\hline \multicolumn{2}{|c|}{ TABLE-2: Dose of Mivacurium Chloride } \\
\hline
\end{tabular}

The intubating conditions were excellent in all the 30 patients in Group-1, whereas in Group2, 18 out of 30 had excellent intubating conditions.Of the remaining 12 patients of Group-2, 7 had good, 3 had fair and 2 had poor intubating conditions at 60 seconds(Table-3).

\begin{tabular}{|l|c|c|c|c|}
\hline \multicolumn{1}{|c|}{ SCORES } & \multicolumn{2}{c|}{ GROUP -I } & \multicolumn{2}{c|}{ GROUP -II } \\
\hline & NO. OF PATIENTS & $\%$ & NO. OF PATIENTS & $\%$ \\
\hline Excellent (8- 9) & 30 & 100 & 18 & 60 \\
\hline Good (6-7) & - & - & 7 & 23 \\
\hline Fair(3-5) & - & - & 3 & 10 \\
\hline Poor (0-2) & - & - & 2 & 7 \\
\hline
\end{tabular}

TABLE-3

$\mathrm{X}^{2}=13.25$, at DF $1, \mathrm{p}<0.001$

The mean duration of action of Suxamethonium was 5.42 minutes with a maximum duration of 8.5 minutes and minimum duration of 3.5 minutes (Table-4), whereas the mean duration of action of mivacurium chloride was 11.02 minutes with a maximum of 14.5 minutes and minimum of 6.8 minutes(Table-5). 
ORIGINAL ARTICLE

\begin{tabular}{|c|c|c|}
\hline DURATION & NO. OF PATIENTS & PERCENTAGE \\
\hline 3.1-5 minutes & 11 & 37 \\
\hline $5.1-8$ minutes & 18 & 60 \\
\hline 8.1-11 minutes & 1 & 3 \\
\hline Mean duration & 5.42 minutes \\
\hline Maximum duration & 8.5 minutes (Case No.29) \\
\hline Minimum duration & 3.5 minutes (Case No's 4, 10 \& 30) \\
\hline
\end{tabular}

TABLE-4 Duration of action of Suxamethonium

\begin{tabular}{|c|c|c|}
\hline DURATION & NO. OF PATIENTS & PERCENTAGE \\
\hline 6.1-9 minutes & 6 & 20 \\
\hline 9.1-12 minutes & 14 & 47 \\
\hline 12.1-15 minutes & 10 & 33 \\
\hline Mean duration & 11.02 minutes \\
\hline Maximum duration & \multicolumn{2}{|c|}{14.5 minutes (Case No.6) } \\
\hline Minimum duration & \multicolumn{2}{|c|}{6.8 minutes (Case No. 9) } \\
\hline
\end{tabular}

TABLE-5: Duration of action of Mivacurium Chloride

In both the groups, there was a significant increase in mean heart rate 1 minute following intubation (Table-6).In Group-I, the maximum increase in the mean heart rate from the preinduction value at 1 minute following intubation was 11.40 beats / minute. In Group-II, the maximum increase in the mean heart rate from the pre-induction value at 1 minute following intubation was 12.14 beats / minute. The mean heart rate gradually declined towards the preinduction value by 5 minutes following intubation in both the groups.

\begin{tabular}{|c|c|c|c|c|c|c|c|}
\hline & \multicolumn{3}{|c|}{ Group-I } & \multicolumn{3}{|c|}{ Group-II } & \multirow{2}{*}{$\begin{array}{l}\text { Unpaired } \\
\text { 't' value }\end{array}$} \\
\hline & $\begin{array}{l}\text { Mean heart rate } \\
\text { beats / minute }\end{array}$ & SE & SD & $\begin{array}{c}\text { Mean heart rate } \\
\text { beats /minute }\end{array}$ & $\mathrm{SE}$ & SD & \\
\hline Base line & 121.13 & 1.65 & 9.02 & 131.46 & 1.76 & 9.64 & 5.81 \\
\hline $\begin{array}{l}1 \text { minute after } \\
\text { intubation }\end{array}$ & 132.53 & 1.62 & 8.86 & 143.60 & 1.77 & 9.70 & 6.25 \\
\hline $\begin{array}{l}3 \text { minutes after } \\
\text { intubation }\end{array}$ & 128.36 & 1.73 & 9.45 & 138.70 & 1.99 & 10.90 & 5.18 \\
\hline $\begin{array}{l}5 \text { minutes after } \\
\text { intubation }\end{array}$ & 124.26 & 1.90 & 10.38 & 135.86 & 2.14 & 11.73 & 5.40 \\
\hline
\end{tabular}

AtDF 58, p $<0.001 \mathrm{HS}$

There was a significant increase in the mean arterial pressure 1 minute following intubation in both the groups (Table-7).In Group-I, the maximum increase in the mean arterial pressure from the pre-induction value at 1 minute following intubation was $8 \mathrm{~mm}$ of $\mathrm{Hg}$.In Group-II, the maximum 
increase in the mean arterial pressure from the pre-induction value at 1 minute following intubation was $14.03 \mathrm{~mm}$ of $\mathrm{Hg}$.The mean arterial pressure gradually declined towards the pre-induction value by 5 minutes following intubation in both the groups.

\begin{tabular}{|c|c|c|c|c|c|c|c|}
\hline & \multicolumn{3}{|c|}{ Group-I } & \multicolumn{3}{c|}{ Group-II } & $\begin{array}{c}\text { Unpaired ' } \mathrm{t} \text { ' } \\
\text { value }\end{array}$ \\
\hline & $\begin{array}{c}\mathrm{mm} \text { of } \\
\mathrm{Hg}\end{array}$ & $\mathrm{SE}$ & $\mathrm{SD}$ & $\begin{array}{c}\mathrm{mm} \text { of } \\
\mathrm{Hg}\end{array}$ & $\mathrm{SE}$ & $\mathrm{SD}$ & \\
\hline Base line* & $82 . .73$ & 1.52 & 8.33 & 80.23 & 1.23 & 6.72 & 2.03 \\
\hline 1 minute after intubation** & 90.73 & 1.38 & 7.55 & 94.26 & 0.86 & 4.68 & 4.12 \\
\hline $\begin{array}{c}3 \text { minutes after } \\
\text { intubation** }\end{array}$ & 85.50 & 1.48 & 8.07 & 91.56 & 1.14 & 6.26 & 5.29 \\
\hline 5 minutes after intubation* & 86.96 & 1.30 & 7.16 & 89.33 & 0.98 & 5.36 & 2.41 \\
\hline
\end{tabular}

*at DF 58, p< 0.05 S; $* *$ at DF 58, p< $0.001 \mathrm{HS}$

DISCUSSION: Prior to the introduction of muscle relaxants inhalational agents were used to achieve intubation. However, this method took long time for achieving adequate intubating conditions and has often associated with the dangerous, life threatening conditions such as laryngospasm, bronchospasm, bradycardia and hypotension.

The introduction of muscle relaxants into the clinical practice has revolutionized the practice of anesthesia.

Suxamethonium, a depolarizing muscle relaxant, produces excellent intubating conditions by 60 seconds and is commonly employed to achieve intubation both in elective and emergency cases.However, it falls short of an ideal muscle relaxant because of its side effects like cardiac arrhythmias and hyperkalemia ${ }^{1}$

In various clinical conditions where Suxamethonium is contraindicated there is a need for a non-depolarizing muscle relaxant which has an onset time similar to that of Suxamethonium but without its side effects.

Mivacurium, anon-depolarizing muscle relaxant, introduced into clinical practice in 1993 has been shown to have a faster onset of action similar to that of Suxamethonium.In view of this, present study was undertaken to compare the intubating conditions of mivacurium with that of Suxamethonium at 60 seconds.

Dosage Selected: One of the methods available to hasten the onset time of non-depolarizing muscle relaxant is to employ it in multiples of $\mathrm{ED}_{95^{2}}{ }^{2}$. It has been found that mivacurium chloride, which has an $\mathrm{ED}_{95}$ of $0.08 \mathrm{mg} \mathrm{kg}^{-1}$ body weight, when employed in multiples of $\mathrm{ED}_{95}$ does not significantly increase the duration of action but lessens the onset time 4 .

Various authors have also shown that, doubling the $\mathrm{ED}_{95}$ of mivacurium from 0.1 to $0.2 \mathrm{mg}$ $\mathrm{kg}^{-1}$ body weight prolonged the duration of action by only 3 minutes and shortened the onset of actions from 3 to 1.7 minutes 5 .

In view of this, as we are attempting to compare the intubating conditions at 60 seconds, we employed a higher dose of mivacurium chloride namely $0.25 \mathrm{mg} \mathrm{kg}^{-1}$ body weight which represents 
$3 \mathrm{X} \mathrm{ED}_{95}$ dose.The dosage of mivacurium employed for intubation in the present study is similar to that employed by various authors $6,7,8$.

The $\mathrm{ED}_{95}$ of Suxamethonium is to $0.33 \mathrm{mg} \mathrm{kg}^{-1}$ body weight.3 $\mathrm{X} \mathrm{ED}_{95}$ dose which approximates $1 \mathrm{mg} \mathrm{kg}^{-1}$ body weight has been employed for intubation in the present study andsimilar doses has been employed by many authors ${ }^{6,8,9,10}$. Thus, in the present study both Suxamethonium and mivacurium were employed in the dose of $3 \mathrm{X} \mathrm{ED}_{95}$ to achieve intubation.

Intubation Time: Various authors have employed either neuromuscular monitoring or clinical criteria for achieving intubation.Those who have employed neuromuscular monitoring for assessing intubating conditions have defined the onset time as the time from injection of the drug to $95 \%$ neuromuscular blockade.

It is found that employing a dose of $0.1 \mathrm{mg} \mathrm{kg}^{-1}$ body weight of mivacurium causes $95 \%$ neuromuscular block at3.8 +0.5 minutes. By employing $0.15,0.2$ and $0.25 \mathrm{mg} \mathrm{kg}^{-1}$ body weight of mivacurium, it was found that 95\% neuromuscular blockade occurred at $3.3+0.2$ minutes, $2.5+0.3$ minutes and $2.3+0.3$ minutes respectively 4 .

Other authors employing a dose of $0.15 \mathrm{mg} \mathrm{kg}^{-1}$ body weight and $0.2 \mathrm{mg} \mathrm{kg}^{-1}$ body weight of mivacurium found the onset time of approximately 1.59 minutes and 1.60 minutes respectively ${ }^{11}$.

However, with non-depolarizing muscle relaxants, it has been found that the onset of paralysis at laryngeal muscles precedes that of adductor pollicis and hence monitoring of train of four at adductor pollicis may not give the correct picture of intubating conditions ${ }^{12}$.

This clearly shows that the paralysis at laryngeal muscles precedes that of adductor pollicis and hence TOF monitoring at adductor pollicis does not given exact picture of adequate intubating conditions ${ }^{13}$.

In view of the above findings, in the present study neuromuscular monitoring was not employed and the intubating conditions were assessed at 60 seconds based on clinical criteria.

Intubating Conditions:In the present study, 30 patients were selected and intubating conditions were assessed at 60 seconds employing $0.25 \mathrm{mg} \mathrm{kg}^{-1}$ body weight of mivacurium and the intubating conditions were assessed employing R Cooper, R.K. Mirakhur et al 1994 classification

It was found, that 18 out of 30 patients, i.e., $60 \%$ of the patients had excellent intubating conditions with good jaw relaxation, vocal cords completely relaxed but no response to intubation except in 2 patients who had slight diaphragmatic movement during intubation with a total score of 8 but falling under excellent grading.

7 patients, i.e., $23 \%$ of the patients had good intubating conditions with good jaw relaxation, vocal cords moving with slight diaphragmatic movement except in 1 patient who had moderate jaw relaxation slight diaphragmatic movement and vocal cords completely relaxed.

3 patients, i.e., $10 \%$ of the patients had fair intubating conditions with good jaw relaxation but vocal cords closing and mild coughing during intubation falling under fair reading with a total score of 5.

2 patients, i.e., $7 \%$ of the total patients had poor intubating conditions with poor jaw relaxation, vocal cords closing and mild coughing and intubation could not be accomplished at 60 seconds. In one of these patients mask ventilation was continued for 30 more seconds and excellent intubating conditions were achieved at 90 seconds. Similarly in another patient mask ventilation 
was continued for 30 more seconds and still intubation at 90 seconds could not be accomplished with inadequate good jaw relaxation being present and therefore mask ventilation continued for another 30 more seconds and excellent intubating conditions were achieved at 120 seconds.

Thus, it can be seen that in the present study be found excellent grading in $60 \%$, good grading $23 \%$, fair grading in $10 \%$ and poor grading in $7 \%$ of patients.

Those authors who also employed $0.25 \mathrm{mg} \mathrm{kg}^{-1}$ body weight of mivacurium and attempted intubation at 60 seconds obtained good to excellent grading in $95.6 \%$ of patients and they have not split the percentage of excellent and good gradings ${ }^{6}$.

In the present study all the 30 patients who received Suxamethonium $1 \mathrm{mg} \mathrm{kg}^{-1}$ body weight had excellent intubating conditions at 60 seconds. Although 1 patient had slight diaphragmatic movement and the score was 8 , it fell under excellent grading which was similar with studies done by other authors $9,8,6,14$.

Thus, Suxamethonium $1 \mathrm{mg} \mathrm{kg}^{-1}$ body weight remains the undisputed drug for achieving excellent intubating conditions at 60 seconds, whereas mivacurium chloride $0.25 \mathrm{mg} \mathrm{kg}^{-1}$ body weight cannot be relied upon for achieving good to excellent intubating conditions at 60 seconds.However, at 120 seconds excellent intubating conditions can be achieved.

Duration of action: The clinical duration of action of mivacurium chloride is one half to one third of intermediate acting non depolarizing muscle relaxants and about 2 to 3 times that of suxamethonium ${ }^{4,15,16 .}$

This short duration of action is due to enzymatic hydrolysis by pseudocholinestrease at 70 $88 \%$ the rate of Suxamethonium ${ }^{4,17}$.

In the present study the clinical duration of action of mivacurium was based on clinical criteria, from the time of injection to the first attempt at breathing and it was found that with a dose of $0.25 \mathrm{mg} \mathrm{kg}^{-1}$ body weight it ranged from a minimum of 6.8 minutes to a maximum of 14.5 minutes with a mean duration of action of 11.02 minutes which concurs with Goldberg et al 19898.

Similarly, the clinical duration of action Suxamethonium $1 \mathrm{mg} \mathrm{kg}^{-1}$ body weight in the present study was found to range between a minimum of 3.5 minutes to a maximum of 8.5 minutes with a mean duration of action of 5.42 minutes which concurs with various authors $8,10,18$.

Cardiovascular changes: In the present study, we noticed a mean increase of heart rate by 12 beats one minute following intubation and systolic blood pressure rose by $14 \mathrm{~mm}$ of $\mathrm{Hg}$, diastolic blood pressure by $14 \mathrm{~mm}$ of $\mathrm{Hg}$ and mean arterial pressure rose by $14 \mathrm{~mm}$ of $\mathrm{Hg}$.There was a gradual decline in heart rate and MAP towards the base line at 5 minutes following intubation.

Similar trends were seen following the administration of Suxamethonium $1 \mathrm{mg} \mathrm{kg}^{-1}$ body weight.At one minute after intubation heart rate increased by 11 beats, systolic blood pressure by 11 $\mathrm{mm}$ of $\mathrm{Hg}$, diastolic blood pressure by $8 \mathrm{~mm}$ of $\mathrm{Hg}$ and mean arterial pressure rose by $8 \mathrm{~mm}$ of $\mathrm{Hg}$.At 5 minutes following intubation a heart rate and blood pressure showed a gradual decline.These cardiovascular changes might be due to laryngoscopic and intubation responses ${ }^{8}$.

Untoward side effects: In the present study, no adverse effects were found with either $0.25 \mathrm{mg} \mathrm{kg}^{-1}$ body weight of mivacurium or in the control group who were given Suxamethonium $1 \mathrm{mg} \mathrm{kg}^{-1}$ body weight which is similar to the studies done by other authors 6,8 . 
CONCLUSION: From the present study it can be concluded that the Suxamethonium $1 \mathrm{mg} \mathrm{kg}^{-1}$ body weight produces excellent intubating conditions uniformly in all the patients at 60 seconds whereas mivacurium chloride $0.25 \mathrm{mg} \mathrm{kg}^{-1}$ body weight provides good to excellent intubating conditions in $83 \%$ of the patients at 60 seconds.

The average duration of action of Suxamethonium $1 \mathrm{mg} \mathrm{kg}^{-1}$ body weight is 5.4 minutes where as that of mivacurium chloride $0.25 \mathrm{mg} \mathrm{kg}^{-1}$ body weight is 11.02 minutes.

When Suxamethonium and mivacurium are compared for aiding intubation at 60 seconds, Suxamethonium remains superior to mivacurium.However, in situations where Suxamethonium is contraindicated mivacurium can be employed for achieving intubation in elective cases.

\section{REFERENCES:}

1. Larach MG, Rosenberg H, Gronert GA et al. hyperkalemic cardiacarrest during anesthesia in infants and children with occult myopathies.Clin Paediatr (phila) 36:9, 1997.

2. Basta SJ, Ali HH, Savarese JJ, et al. Clinical pharmacology of atracurium besylate: a new non depolarizing muscle relaxant.Anaesth A 1982; 61:723 -729.

3. Hunter JM, Jones RS, Utting JE. Comparison of vecuronium, atracurium and tubocurarine in normal patients. British Journal of Anaesthesia.1984; 56:941-950.

4. Savarese JJ, Ali HH, Basta SJ et al.The clinical neuromuscular pharmacology of mivacurium chloride.A short acting non depolarizing ester neuromuscular blocking drug.Anaethesiology 1988; 68:723 -732.

5. Goudsouzian NG, Allifimoff JK, Eberly C et al.Neuromuscular and cardiovascular effects of mivacurium in children.Anaesthesiology 1989; 70:237 - 242.

6. Fuentes de Frutos AL, Muriel Villoria C, Romo Cortina MT. Conditions of intubation and neuromuscular block induced by mivacurium: Comparison with succinylcholine. Rev. Esp Anesthesiol Reanim 1999; Apr 46(4):143-8.

7. Lin SM, Chu YC, Lur JY, Lin SH et al.The neuromuscular effects ofmivacurium in adults with priming technique during nitrous oxide - Fentanyl anaesthesia:a randomized comparative study with succinylcholine. Acta Anaesthesiol.Sin 1998; 36(2): 75 - 80

8. Goldberg ME, Larijani GE, Azad SS et al. Comparison of tracheal intubating conditions and neuromuscular blocking profiles after intubating does of mivacurium or succinylcholine in surgical out patients.Anaesth, Analg. 1989; 69:93-9.

9. Jun Tang MD, Girish P. Joseph, Paul F.White.Comparision of rocuronium and mivacurium to succinylcholine during outpatientlaparoscopic surgery.Anaesth. Analg. 1996; 82:994-998.

10. Naguib M, Samarkandi AH, Ammar A and Turkistani A.Comparision of suxamethonium and different combinations of rocuronium and mivacurium for rapid tracheal intubation in children.British Journal of Anaesthesia, 1997; 79:450-455.

11. Maddineni VR, Mirakhur RK, McCoy EP, et al. Neuromuscular effects and intubating conditions following mivacurium, a comparison with suxamethonium.Anaesthesia. 1993; 48: 940-945.

12. Donati F, Plaud B, Meistelman C. Vecuronium neuromuscular blockade at the adductor muscle of larynx and adductor pollicis.Anaesthesiology 1987;67:326. 
13. Sayson SC, Mongan PD. Onset of action of mivacurium chloride: a comparison of neuromuscular blockade monitoring at the adductor pollicis and the orbicularis occuli.Anaesthesiology 1994;81(1):35 - 42.

14. Mangat PS, Evans DEN, Harmer M, Lunn N.A comparison between mivacurium and suxamethonium in children, Anaesthesia 1993; 48:866-869.

15. Diefenbach C, Mellinghoff H, Lynch I et al. Mivacurium: dose - responserelationships and administration by repeated injection or infusion. Anaesth. Analg1992; 74: 420.

16. Caldwell JE, Heir T, Kitts JB et al. Comparison of neuromuscular block induced by mivacurium, suxamethonium and atracurium during $\mathrm{NO}_{2}$ - Fentanyl Anesthesia. British Journal of Anesthesia 1989; 63: 393.

17. Cook DR, Stiller RL, Weakly NI. In vivo metabolism of mivacurium chloride and suxamethonium.Anesth Analg 1989; 68: 452.

18. Brandom BW, Woelfel SK, Cook DR et al. Comparison of mivacurium and suxamethonium administered by bolus and infusion. British Journal of Anaesthesia, 1989; 62:488-493.

\section{AUTHORS:}

1. Vasantha Kumar J

2. Dayananda V.P.

3. G.S. Venkatesh

\section{PARTICULARS OF CONTRIBUTORS:}

1. Assistant Professor, Department of Anaesthesiology, Bangalore Medical College and Research Institute.

2. Assistant Professor, Department of Anaesthesiology, Bangalore Medical College and Research Institute.

3. Professor, Department of Anaesthesiology, Mysore Medical College and Research Institute.

\section{NAME ADDRESS EMAIL ID OF THE} CORRESPONDING AUTHOR:

Dr. Vasantha Kumar J., \#11, $1^{\text {st }}$ Floor, $1^{\text {st }}$ Cross, Chinnamma Layout, Cholanayakanahalli, R.T. Nagar Post, Bangalore - 560032.

Email-drvjk.yash@gmail.com

Date of Submission: 07/12/2013. Date of Peer Review: 09/12/2013. Date of Acceptance: 27/12/2013. Date of Publishing: 08/01/2014 